\title{
The recognizability and consequentiality of mistakes: Some notes on the article by Klemp et al.
}

Oskar Lindwall, Bryn Evans and Claes Reit

\section{OpenEdition}

12 Journals

\section{Electronic version}

URL: http://journals.openedition.org/educationdidactique/2700

DOI: $10.4000 /$ educationdidactique. 2700

ISSN: $2111-4838$

Publisher

Presses universitaires de Rennes

\section{Printed version}

Date of publication: 20 June 2017

Number of pages: 133-137

ISBN: 978-2-7535-6460-2

ISSN: 1956-3485

Electronic reference

Oskar Lindwall, Bryn Evans and Claes Reit, « The recognizability and consequentiality of mistakes:

Some notes on the article by Klemp et al. », Éducation et didactique [Online], 11-1 | 2017, Online since 20 June 2019, connection on 10 December 2020. URL : http://journals.openedition.org/ educationdidactique/2700; DOI : https://doi.org/10.4000/educationdidactique.2700 

MISTAKES: SOME NOTES ON THE ARTICLE BY KLEMP ET AL.

\author{
Oskar Lindwall \\ University of Gothenburg, Sweden \\ Bryn Evans \\ Auckland University of Technology, New Zealand \\ Claes Reit \\ University of Gothenburg, Sweden
}


In a documentary called Attrazione D'amore, the cinematographer Frank Scheffer provides footage from a lunch concert at Amsterdam's Royal Concertgebouw. When the orchestra starts to play Mozart's Piano Concerto No. 20 in D minor, it becomes apparent that the renowned pianist Maria João Pires had made a mistake. As the director of the concert, Riccardo Chailly, recounts in the film:

"She was shocked because she was expecting us to play another concerto. So when I started the first bar of the D-minor concerto she kind of jumped and panicked like an electroshock and she couldn't consider even moving ahead playing. Then we talked a moment and she told me that 'was expecting to play a completely different piece. I do what I can do - if I remember.' And the miracle is that she has such a memory that she could, within a minute, switch to a new concerto without making one mistake."

A couple of years after the documentary was first broadcast, the film was uploaded and re-discovered by an audience online ${ }^{1}$. The popularity of the clip partly can be explained by how the camera captures the strong and changing emotional displays of Maria João Pires, which continue after she starts playing and become a part of her performance of the concerto. Even though she had made a mistake, it is a mistake that she recovers from, and the resulting performance arguably turns out to be more powerful than it would have without the mistake. As we read and discussed the article by Klemp et al. (2016), we talked about this and other mistakes, including mistakes we had made ourselves, that we had seen others make, and that we had analyzed as part of our research on dentistry, sports, and education. We found the approach of the article stimulating, especially in its emphasis of the insights of practitioners - in this case jazz musicians - over the theoretical distinctions commonly found in the research literature on errors and mistakes.

A substantial portion of the research on human errors has been conducted from within the traditions of cognitive science and human factors. In a manner characteristic of these traditions, Reason (1990) distinguishes between three types of mistakes: errors of planning, errors of storage, and errors of execution. People, that is, might come up with the wrong plan, forget the plan they had, or fail to execute the plan as they intended. Classifications like these appeal to commonsense and are commonly applicable to a wide range of situations. Maria João Pires had brought the wrong sheet of music to the concert hall. Not being able to rely on any written notes, she had to depend on her familiarity with the concerto. She had played it with the orchestra during the previous season and, as a distinguished Mozartian, she had undoubtedly played it numerous times before. Nevertheless, her ability to rely on her "memory" and "switch to a new concerto without making one mistake" was still found to be a miracle by the director. Using the terminology of Reason (1990), Maria João Pires made an error in planning, but miraculously no error in storage or execution.

Cognitivist conceptions of mistakes, of the type suggested by Reason (1990), are labeled the "standard view" by Klemp et al.: "The standard view is that a mistake is the same as an error, a break from plan due to a faulty head or hand. It is to be avoided, recontextualized, hidden, or conceded with chagrin as an embarrassment." (2016, p. 110) This perspective is contrasted with the approach they themselves propose. Their critique of the standard view draws on two sources: on the one hand, academic conceptions of action that are different from, and proposed as alternatives to, cognitive theorizing; and on the other, jazz music and jazz musicians' expressed understandings of their own improvised performances.

There are clear parallels between the ways in which Klemp et al. develop their critique and how theories of "situated learning" and "situated cognition" (e.g., Lave \& Wenger, 1991; Brown, Collins \& Duguid, 1988) were proposed as alternatives in the field of education. In both cases, there are strong ties to the analytic histories of studies of situated action and particularly to ethnomethodology and conversation analysis. Moreover, in both cases, the introduction of a new domain is instrumental for the suggested shift in perspective. In the case of situated learning, the move was one from cohort organized teaching in classrooms to apprenticeships. The notion of information transfer might make some sense in classrooms, as the teacher is saying things that the students then should remember on later occasions, but it seems harder to apply to the less formal settings in which apprentices train. Similarly, the terminology of plans and executions is much more easily applied to a piano concerto than it is to an improvised jazz performance. In contrast to the 
Oskar Lindwall, Bryn Evans \& Claes Reit

former case, a wrong note in the latter "is errant only to what has already happened, and it can be made less errant by rearranging what happens next" (Klemp et al., 2016, p. 110).

A central message of Klemp et al.'s paper is that when we listen to an improvised jazz performance, "we hear neither plans, nor mistakes, but takes in which expectations and difficulties get worked on in the medium of notes, tones and rhythms." (ibid.) Following this, one could perhaps argue that most of our lives, including our engagement in mundane conversations, is more like improvised jazz than a piano concerto. We are not following scripts so much as adapting, moment-by-moment, to changing circumstances, thereby being reflexively involved in changing those circumstances (cf. Suchman, 1987). The question remains, however, how far the insights drawn from improvised jazz are applicable to other fields of conduct. The variation with regards to plans, takes, and mistakes seem to be endless, and, in particular, our discussions about this question tended to circulate around two interconnected themes: how the recognizability of mistakes, including those that Klemp et al. reconceptualise as mis-takes, are unavoidably tied to criteria and the wide variety of consequences that they engender.

Klemp et al. (2016) do not want to call the note played by Thelonious Monk that they carefully analyse in the article an error; hence they introduce the notion of mis-take in place of mistake. In the recording they hear "signs of struggle" (p. 106), which set up "a challenge for Monk and his listeners" (p. 107). We have listened for these signs and discussed in what ways the passage was challenging to us. The three of us have different experiences of jazz music, music theory, and musical notation: one is completely unfamiliar with these domains, one has some passing knowledge, and the third has more substantive knowledge of both theory and practice. Notably, this did not seem too decisive for whether we heard a mis-take in the solo by Monk. Sometimes we heard it, other times we did not. But it had consequences for how we heard the note in its sequential context, for how we accounted for hearing or not hearing the mis-take, and for our ability to follow, understand, agree, or disagree with the analysis of the note by Klemp et al.

As the authors note: "Any note might be a mistake or not depending on context, the rules of harmony, the player's intention or the audience's expectations." (ibid.). Without access to what Monk intended to do, and given that Monk's style of playing could be challenging for an audience without him necessarily making any mistakes, the issue of what constitutes a mistake becomes complicated. In a Mozart concerto, the criteria for making such judgments are easier to formulate. In general, however, the distinction between success and failure, like the distinction between a take and a mistake, is often hard to draw and contingent on criteria that are impossible to fully specify. In dentistry, for instance, the difference between a root canal filling that is "good enough" and one that cannot be accepted and has to be redone is not only tied to technical quality, but also to risks of complications, the skill of the dentist, the cooperation of the patient, economic factors, et cetera (Dahlström et al. 2017). Dentists regularly express that it is almost impossible to tell whether they have succeeded with a root canal filling or not: despite everything going according to plan, and radiographs and other evidence indicating that the procedure was executed correctly, the patient nevertheless might return with symptoms a couple of months later.

Many mistakes, in medicine and life more generally, are tied to risks and circumstances over which people have little control. It is only in hindsight and through their consequences that these mistakes emerge. Returning to the $\mathrm{D}$ minor piano concerto by Mozart discussed earlier, it could have been argued at the time of its original performance on February 11th, 1785 that the composer, in selecting the piece for his Viennese audience, was making a serious mistake. Prior to this performance, Mozart had respected the convention of treating instrumental concertos as pure entertainment. One can then only imagine the reaction of the audience that night when they listened to his first concerto in a minor key, and were faced with aching anxiety and shadows from the world of the doomed; shivers of fear from the cellos and the deep of the double basses; crushing loneliness. Certainly in making this decision Mozart took a major risk. If the picky Viennese nobility, on whose financial support Mozart depended, disliked the piece he stood to lose their favor. In retrospect, however, it is clear that by breaking the rules Mozart transformed the piano concerto forever, from joyful entertainment into a vehicle for deep emotional reflection. Perhaps this was something that Mozart envisioned, but he had to wait to find out how the audience would respond to this break with their expectations. 
A mistake's consequentiality depends thoroughly on the retrospective and prospective relations within which it is embedded and to which it contributes. Klemp et al. draw attention to how takes and mis-takes, as concrete social phenomena, are inevitably produced, recognized, and responded to within courses of situated, temporally unfolding activities: "Moments, like notes played on a keyboard, become consequential - even momentous - by their simultaneous connections to things that have already happened and are about to happen." (2016, p. 106) Within such contextures of activity, the occurrence of a mistake is consequential in and as of the significance it has for involved parties in shaping their understandings of what just happened and what they should do next. Just what is projected as a mistake's relevant next move, and just who is obligated or entitled to respond, are thus subject to enormous variability depending on the locally oriented details of the mistake, its circumstances, and the identities and relations of the parties to it.

The different action-recognition-response sequences distinguishing Thelonious Monk's mistake, Maria João Pires'saved mistake and Mozart's could-have-been mistake illustrate the central point that mistakes possess an occasioned consequentiality, a feature that can ramify: the Boston Globe ${ }^{2}$ reports on a 74-year-old woman undergoing a routine medical procedure to relieve back pain during which the attending neurosurgeon mistakenly injected into her spine a dye not intended for intracathel use. The surgeon immediately admitted the mistake to the patient's sons; the patient died; hospital and government inquiries were launched; the insurer's lawyers sent letters to the sons denying a mistake was made; a lawsuit was launched and settled; and the hospital instituted new procedures designed to prevent similar future mistakes. Indeed, the occurrence of a mistake can itself occasion the reflexive reconstruction of the very circumstances in which it is embedded. In an article describing his experience of playing pick-up basketball, Macbeth (2012) recounts an occasion when, in possession of the ball and moving towards the basket, he spots another player apparently mirroring his own pace and trajectory of movement, and experiences the emergence of a joint enterprise: both players, with synchronized purpose, creating an "opening". When Macbeth passes the ball to the second player, however, he discovers the player to be a member of the opposing team. In the surprised response of the player receiving an unexpected pass, the pass becomes a mistake, the "teammates" become reconfigured as opponents, the cultivated synchrony of their bodies becomes a coincidence, and the 'opening' is revealed as a chimera.

Klemp et al. (2016) include the following epigraph, attributed to "Drummer E. W. Wainwright (conversation with Klemp, 2001)": "A mistake is the most beautiful thing in the world. It is the only way you can get to some place you've never been before. I try to make as many as I can. Making a mistake is the only way that you can grow."(p. 106). Such formulations of mistakes have a resonance and relevance for certain types of contexts, and reconstructing a context within which this formulation constitutes a reasonable description of mistakes becomes part of the work of understanding the epigraph. Here the attribution of the quotation's source forms a central detail of its structure of intelligibility. The quotation and its attribution function together to comprise a particular configuration of category of actor (drummer), setting (ethnographic interview), and course of action (being asked for and providing a response to an interview question, which itself involves the production of an account of the work of being a musician). Within this reconstructed context, the description of mistakes as beautiful and productive things seems apt, even instructive. But given a differently categorized source and course of action, say "Neurosurgeon Dr. Steven Hwang (malpractice hearing, 2014)", the identical quotation may occasion an alternative uptake by the reader.

All of this is to say that recognizing a mistake, determining one's relation and stance to it, and working out one's response, all as part of a temporally-unfolding contexture of activity, is the work of mistakes, in and as the situated reasoning and action of relevant parties. This work involves the competency to apply the criteria to recognize a mistake and its occasioned consequentiality. Experts, like Monk, already own the criteria. But how about those who do not? For us, that is the central issue that ties together mistakes, competence, and instruction.

Toward the end of their article, Klemp et al. argue that in schools student mistakes often are recorded and used to sort students institutionally: "the very place that promises learning produces also constant and often debilitating failure" (2016, p. 116). Although this function of mistakes is present in schools, the recognition of student mistakes 
Oskar Lindwall, Bryn Evans E Claes Reit

is also integral to teaching and learning in many cases. In an article on classroom discourse as improvisation, Erickson notes: "Mistakes are inevitable, since the students are learners; learning is by definition the acquisition of mastery, not the possession of it. The opportunity to learn is the opportunity to make mistakes. Moreover, student mistakes provide the teacher with the opportunity to teach." (1982, p. 161). In our own work on basketball coaching and the teaching and learning of craft (e.g., Evans \& Reynolds, 2016; Lindwall \& Ekström, 2012), much of the teaching that goes on is occasioned by various mistakes, and takes the form of correction, without this necessarily being oriented to as failures on behalf of the learners. Learning by doing necessarily implies that learners engage in activities before they are able to perform or assess these activities in competent ways. By allowing learners to do that, and by treating mistakes as an inevitable part of learning, instructors are provided with a powerful resource for teaching.

\section{NOTES}

1. [https://www.youtube.com/watch?v=CJXnYMl_SuA].

2. [https://www.bostonglobe.com/lifestyle/health-wellness /2014/08/30/surgical-error-tufts-medical-center-promptswidespread-changes-operating-rooms/8JFgKrx6FIvLLT6Uja2bkJ/story.html].

\section{RÉFÉRENCES}

Brown, J. S., Collins, A., \& Duguid, P. (1989). Situated cognition and the culture of learning. Educational Researcher, 18(1), 32-42.

Dahlström, L., Lindwall, O., Rystedt, H., \& Reit, C. (2017). 'It's good enough': Swedish general dental practitioners on reasons for accepting substandard root filling quality. International Endodontic Journal. Advance online article: doi: 10.1111/iej.12743.

Erickson, F. (1982). Classroom discourse as improvisation: Relationships between academic task structre and social participation structure in lessons. In L. C. Wilkinson (Ed.), Communicating in the classroom. Madison, WI: University of Wisconsin Press.

Evans, B., \& Reynolds, E. (2016). The organization of corrective demonstrations using embodied action in sports coaching feedback. Symbolic Interaction, 39(4), 525-556.

Lave, J., \& Wenger, E. (1991). Situated learning: legitimate peripheral participation. Cambridge, MA: Cambridge University Press.

Lindwall, O., \& Ekström, A. (2012). Instruction-ininteraction: The teaching and learning of a manual skill. Human Studies, 35(1), 27-49.

Klemp, N., McDermott, R., Duque, J., Thibeault, J., Powell, K., \& Levitin, D. J. (2016). Plans, takes, and mis-takes. Éducation \& Didactique, 10(3), 105-120.

Macbeth, D. (2012). Some notes on the play of basketball in its circumstantial detail, and an introduction to their occasion. Human Studies, 35(2), 193-208.

Reason, J. (1990). Human error. Cambridge, UK: Cambridge University Press.

Suchman, L. A. (1987). Plans and situated actions: the problem of human-machine communication. Cambridge, MA: Cambridge University Press. 